\title{
Analysis of the Current Situation of the Information Development of Agriculture and Animal Husbandry Industry in Inner Mongolia
}

\author{
Haiying LIN \\ Business School of Inner Mongolia University of Finance and Economics, Inner Mongolia, China \\ Wenlong LI \\ School of Resource and Environment of Inner Mongolia University of Finance and Economics, Inner \\ Mongolia, China
}

\begin{abstract}
Agriculture informationization is an important part of national economy and social informationization. It is also an important work of construction of new rural and pastoral areas. Based on analysis of the current development of the present stage of informationization construction of agriculture and animal husbandry in Inner Mongolia, taking the city of Xilinguole as a case, we are going to find out the existing problems of informationization of agriculture and animal husbandry in Inner Mongolia and therefore propose relevant countermeasures of development which are expected to have a practical significance to the development process of agriculture and animal husbandry in Inner Mongolia.
\end{abstract}

KEYWORD: Agriculture informationization, current situation, Countermeasures, Inner Mongolia

\section{THE BASIC FEATURES OF PRESENT STAGE OF INFORMATIONIZATION CONSTRUCTION OF AGRICULTURE AND ANIMAL HUSBANDRY}

\subsection{Agriculture and animal husbandry comprehensive information service system for engineering construction has roughly formed a scale.}

In the first place, a pilot work of agriculture and animal husbandry informationization has an obvious and remarkable effect. Based on the summary of experience of pilot work in $\mathrm{Wu}$ Yuan county, the whole pilot work is promoted comprehensively and receives good results. In the second place, to serve the "three rural" as the goal, the pilot work integrated agriculture-related departments of agricultural information service network system at all levels, accelerated the "gold farming" project and achieved remarkable success. With the feature of "multinetwork, one agricultural school", the support of Information service covering through the entire process of agricultural and animal husbandry production and the guide of types of information technology means, comprehensive information service system of agriculture and animal husbandry for which intermediary service organizations provided a guarantee under government supervision is being formed.

\subsection{The construction of information infrastructure is becoming maturing.}

With the continuous improvement of information and communication facilities of the autonomous region. Agriculture and animal husbandry information system in our region has made significant progress in construction work. Firstly, "every village telephone installation project" has achieved remarkable success. Secondly, the modern distance education project for the Chinese Communist Party cadres has made substantial progress.

\subsection{Information service system maturing, information services has been greatly improved.}

At present, Agriculture and Animal Husbandry Bureau of 12 Union City of in the autonomous region have set up a market information department and 5 of them established the information center. There were altogether 600 villages and towns established a rural pastoral information service station, which accounted for $78 \%$ of the total towns. Professionals, part-time agricultural information management services personnel reach more than 600 people. There are 653 experts for "12316" three rural service hotline. Rural and pastoral information workers are more than 6,000 people. Initially built agricultural information system provides the organizational guarantee for the informationization construction of agriculture and animal husbandry. 
2 ANALYSIS OF THE CURRENT DEVELOPMENT OF INNER MONGOLIA AGRICULTURE AND ANIMAL HUSBANDRY INFORMATIONIZATION.

\subsection{Awareness of the importance of agriculture and animal husbandry informationization has to be strengthened.}

Awareness of some department leaders in some areas to the importance of the work of agriculture and animal husbandry informationiization is not high and they are lack of efforts, especially in lacking of enough systematic understanding of the importance, urgency, arduousness, complexity and long-term of agriculture and animal husbandry informationiization construction. Some of them even do not know the objective requirement of the transformation of government functions to enhance the administrative ability under the market economy condition and not even realize that it is a strategic choice of the comprehensive construction of well-off society of urban and rural economic and social development with vigorous promoting of the agriculture informationization, using information technology to stimulate the modernization of agriculture and animal husbandry, but still use the traditional agriculture and animal husbandry in thinking and means to command the agricultural and animal husbandry production.

\subsection{Lacking of effective agricultural information resources development and integration mechanism and Information resource sharing.}

Agriculture and animal husbandry involves a wide range, covering the broad information. All levels of Department of farming and animal husbandry and agriculture related departments have their own information resources.

\subsection{Sluggish Information release channels and serious problem of the urban-rural "digital divide".}

For one thing, at present, most agricultural and animal husbandry information platform in our district and Union City County has not been established. The vast majority of rural villages lack the means of network communication and terminal equipment. The problem of "last kilometer", agriculture and animal husbandry entering villages and peasant households, has become a bottleneck of development of informationization. For another, the grass-roots farming and animal husbandry department information release channels are less and it is lack of coordination and communication between the media in the dissemination and release of information of agriculture and animal husbandry. Finally, agricultural departments at all levels are very low level of e-government. Online interactive service work between the government and agricultural and animal husbandry producers and traders have not yet started.

\subsection{Lag of team construction of information staff and necessary quality promotion.}

Information work is a new work. Personnel engaged in information work at all levels of agriculture and animal husbandry departments can't adapt agriculture informationization demand in quantity, structure and overall quality. Reasons are as follows. Firstly, lack of knowledge of information management, managers cannot keep up the pace of development. Secondly, application of the modern information technology of grassroots information service personnel is generally low. Information staff at all levels is mostly part-time. Thirdly, application of the modern information technology of grassroots information service personnel is generally low which is incompatible with high-tech information technology development. Finally, lag of personnel training.

\section{CASE STUDY----THE INFORMATIZATION BUILDING OF THE AGRICULTURE AND HUSBANDRY IN XILIN GOL LEAGUE AND CHIFENG CITY}

\subsection{The informatization of agriculture and husbandry in Xilin Gol League}

The agriculture and husbandry in Xilin Gol League is undergoing a rapid building of informatization which will change the production and life of the rural and pastoral areas. The convenient network information and news reinvigorate and push forward the economic and social development of rural and pastoral areas.

\subsubsection{Information service system and infrastructure of agriculture and husbandry have been strengthened}

In recent years, with the gradual deepening of construction of informatization, the information building of agriculture and husbandry in Xilin Gol League develops rapidly, and the infrastructure has been significantly improved, especially after the implementation of broadcast television, access electricity, TV and telephone for every village. These projects have effectively improved the coverage of broadcast television, the penetration rate of fixes telephone and mobile phone in rural and pastoral areas. Except for a few remote and isolated areas, 95 percent of the rural and pastoral areas have phones and internet. According to statistics, more than 2100 families in pastoral area have installed internet. What's more, the government of cities and 
counties have opened their government portals, and set up agriculture and husbandry information service platform, including agriculture and husbandry information service network and technology information service network, which means that the information service system of agriculture and husbandry has formed. This promotes the application of information technology to economy and social development in rural and pastoral areas and the development of information service that related to agriculture and husbandry.

\subsubsection{Agriculture and husbandry informatization building has achieved some success}

Informatization in Xilin Gol League is gradually changing the way of production and life in rural and pastoral areas. It has promoted the economic development in these areas and has influenced tremendously the whole agriculture, husbandry, famers and herdsmen. All this can be found from the following facts: first, informatization provides technology, education and some other services for farmers and herdsmen, and improves their ability of acquiring and using the information and promotes the construction of new countryside and new pastoral area. Second, the development and application of information related to farming agriculture and husbandry has been enhanced. The production, processing, sales and market supply and demand of agricultural products and livestock and all other information related to farmers' life has begun to take shape. Farmers and herdsmen can easily access all kinds of service information via the internet, mobile phone, radio and TV. Third, the information application capabilities gradually improved. Cities and counties are exploiting agricultural geographic information system, promoting digital development for agriculture and husbandry. Through the complex utilization of agricultural information resources and the application of multi-disciplinary technologies, they have further improved the management of modernization of agriculture and husbandry.

\subsection{The problems for the construction of agriculture and husbandry information in Xilin Gol League}

The foundation of agriculture and husbandry informatization is relatively poor, and the development is unbalanced. There exists wide gap between urban and rural areas in development and utilization of information resources, promotion of information technology and the cultivation of information talents. It even shows the trend of expansion.

\subsubsection{Relatively weak infrastructure and insufficient investment for informatization of agriculture and husbandry}

First, limited by the economy, the investment on infrastructure for informationition in agriculture and husbandry is not enough. The lack of fund restrict the further development of information resources, the implement of information service and employment of technical equipments. Second, the existing infrastructure can not meet the needs of informatization building in rural and pastoral area. The internet penetration rate and its application level is still very low, the broadband access is not strong, even some of the towns and villiages are unable to get access to the internet. On the other way, the viewing capacity of some local government running TV program is poor, a majority of farmers and herdsmen is still using civil satellite receivers to watch TV, and cable penetration rate is still very low in rural and pastoral areas. Third, the information resources in Mongolia language are relatively deficient. There are few of websites of Mongolia language, and the existing few website is suffering from lack of rich column and content and social concern.

\subsubsection{Insufficient understanding of informatization}

Relevant departments have not fully understand the importance of information construction, some misunderstood it. The shortage of manpower, material and financial investment seriously affects the development of informatization.

\subsubsection{Scarcity of IT talents}

Xilin Gol League is facing the scarcity of compound talents for the information technology development of agriculture and husbandry. Personnel working in information cannot meet the needs of grassroots information services both from the quantity and quality level. The current network infrastructure and professional workers cannot follow the everchanging development of information.

\subsubsection{The terminal application of informatization is still in its infancy and the ability of applying information is low in rural and pastoral areas}

First, the overall scientific and cultural qualities of famers and herdsmen are low, so is their ability of receiving and applying information. Second, the low income of farmers and herdsmen leads to the low level of information consumption. Third, the low affordability makes it impossible to access broadband, so the network penetration rate remains low, which becomes the bottleneck for the terminal development of information. 


\subsubsection{The absence of effective integrated mechanism for development of agricultural and husbandry information and the low resources sharing}

Agriculture and husbandry involve a wide field and its information covers is extensive. The agricultural and husbandry departments and the related departments in different cities and counties have their own information resources, while their communication and coordination is poor, so most of the information are close to other departments, they need effective integration.

\section{STRATEGIES FOR INFORMATIZATION OFINNER MONGOLIA AGRICULTURE AND HUSBANDRY}

\subsection{Increase financial input}

Providing effective information services for agriculture, rural areas and famers is not only a wide range of social welfare, but also an effective way to guide farmers to adjust the agricultural structure and increase economic income. We have to increase the investment, strive for the establishment of a special fund in the budget, and raise the funds with the development of this cause. We also have to regulate the funds in related business expenses to ensure the timely and sufficient funds for the construction of information network.

\subsection{Strengthen the system, emphasize the inter- section collaboration, form real pool efforts}

According to the specific implementation of Wuyuan County's project, we should formulate detailed rules, fund management methods, and acceptance check ways for the project to provide rules for it to follow. At the same time, establish a strict reward and punishment system, rewarding the good and fining the bad to fully mobilize the enthusiasm of relevant workers. In a word, we should see to it that the project will be completed with high starting point, high standards and high quality.

\subsection{Strengthen training, improve the quality of agricultural information service personnel}

Take measures to extensively train the personnel computer skills through multichannel and multiform. Meanwhile, for the professional worker of agricultural information in counties, we should enhance the training of computer software design, network maintenance and information analysis and forecasting to improve their knowledge and technical skills, and ensure their master of modern skills to promote the agricultural work.

\section{REFERENCES}

[1] Maowei-Zheng2011. The Correlation Analysis between Health Expenditure of Rural Residents and Per Capita Net Income-Taking Jilin Province as an Example. Research on the theory of Finance and Economics(1):92-96.

[2] Shuxia-Hou, Haiying-Lin2015. Analyze the Change Interests Appeal of Farmers' Professional Cooperative Economy Organization Members On the Dilemma Model in Western Areas. Research on the theory of Finance and Economics(01):51-58.

[3] Yuanyuan-Li2010.Study of the policy changes in Inner Mongolia Pastoral Area and agriculture and animal husbandry development. Research on agricultural modernization31(1): 15- 18.

[4] Haiying-Lin,Wenlong-Li2014. Study on Intensive use of Agricultural land from the Perspective of Industry Transfer Inner Mongolia. Research on the theory of Finance and Economics(05):75-81. 